\title{
Ventricular Quadrigeminy by ECG Finding
}

National Cancer Institute

\section{Source}

National Cancer Institute. Ventricular Quadrigeminy by ECG Finding. NCI Thesaurus. Code C120620.

An electrocardiographic tracing demonstrating three normal QRS complexes followed by a premature ventricular contraction over the course of three or more consecutive cycles; a regularly irregular rhythm of normal to abnormal QRS complexes in a 3-1 ratio. 